\title{
Verification of Euler Type II Reference Hyetograph for Modeling the Sewage Systems in Wroclaw (Poland)
}

\author{
Katarzyna Wartalska, Bartosz Kaźmierczak, Monika Nowakowska, and Andrzej Kotowski
}

\begin{abstract}
The aim of the research was the verification of Euler type II model rainfall used so far in modeling storm water drainage operation in Poland. Rainfall data from measurement stations in Wroclaw were used. For further analysis, rainfalls were selected on the basis of exceedance frequencies. Rainfalls were grouped with the use of cluster analysis: Ward and k-means methods. Especially the k-means method has proven to be useful for selecting precipitation in terms of hyetographs' shapes. On the basis of clustering results, 51 precipitation were selected for verification of Euler type II standard. The statistical analysis of hyetographs shapes similarity was based on 6 parameters defined in the paper. The comparative analysis revealed that, despite some discrepancies, Euler type II model rainfall is suitable for the description of rainfall in tested station.
\end{abstract}

Index Terms-Rainfall, rainfall modeling, rainfall models, storm water drainage.

\section{INTRODUCTION}

Extreme weather events, such as floods, droughts, and tornadoes, which are becoming more frequent, are the result of observed climate change [1]. The urban floods of the Flash Flood type, or the Urban Flood caused by heavy rainfall lead to damage in urban areas. Real environmental threats caused by floods from sewage systems can be identified either during their operation or demonstrated by hydrodynamic modeling. Models for simulating the operation of sewage systems allow, among others, taking into account the time and space variable scenarios of rainfall loads. These scenarios can be both real, measured over many years of intense local precipitation, which is generally hardly available, and model precipitation (in Poland most often Euler type II) created on the basis of local intensity curves IDF (Intensity-Duration-Frequency) or height - DDF (Depth-Duration-Frequency) [2]-[6].

Model precipitation is used in hydrological or hydrodynamic models of the rainfall-runoff phenomenon in the form of individual model precipitation or groups thereof [7]-[9]. The choice of rainfall catchment loading scenario in the modeling of sewage systems is an important problem because the diversity of local precipitation significantly

Manuscript received November 17, 2019; revised March 20, 2020. This work has been carried out as part of the statutory activity of the Faculty of Environmental Engineering at Wroclaw University of Science and Technology, funded by the Ministry of Science and Higher Education.

The authors are with the Department of Water Supply and Sewerage Systems, Faculty of Environmental Engineering, Wroclaw University of Science and Technology, 50-370 Wroclaw, Poland (e-mail: katarzyna.wartalska@pwr.edu.pl,_bartosz.kazmierczak@pwr.edu.pl, monika.nowakowska@pwr.edu.pl, andrzej.kotowski@pwr.edu.pl). affects the uncertainty in obtaining reliable modeling results of the outflow stream from urbanized catchments.

The purpose of the research undertaken is to verify the shape of Euler type II reference hyetograph used so far to model the operation of storm water drainage in Wroclaw (Poland).

In Polish literature, there are few papers on the distribution of rainfall intensity in time and space, especially for the needs of storm water drainage modeling. Hence, the most commonly used distributions are based on many years of precipitation observations in other countries, such as DWA standards (Deutsche Vereinigung für Wasserwirtschaft, Abwasser und Abfall e. V.) [7] or DVWK (Deutscher Verband für Wasserwirtschaft und Kulturbau) [8] developed in Germany or also SCS (Soil Conservation Service) [10] - in the USA. The DWA model, called the Euler type II pattern, is based on the assumption that the largest instantaneous $(\Delta t=5 \mathrm{~min})$ precipitation intensity $(i)$ from IDF curves, occurs at the end of one-third of the duration of the precipitation.

Many methods for creating reference hyetographs are described in the literature. Their general division has been presented, among others in the works of Chow [11], Venezziano and Villani [12], Lin [13], and S. Cazanescu and R.A. Cazanescu [14]. These methods can be divided into 3 groups: methods based on IDF/DDF curves, methods based on historical rainfall data and stochastic methods - still in the phase of experiments. The oldest method based on IDF/DDF curves is the Keifer and Chu method [15], also known as the Chicago method. The hyetograph created on the basis of this method is characterized by a single peak of maximum precipitation intensity. Keifer and Chu, for the Chicago area, determined the dimensionless value of the peak location $\left(t_{i} / T\right)$ as $r=0.375$ - for the considered duration of precipitation: $t \in\{15 ; 30 ; 60 ; 120\}$ minutes. The hyetograph created on the basis of the Keifer and Chu methodology has a continuous form - not suitable directly for use in the modeling of the rainfall-runoff phenomenon, where the discrete form of hyetographs is required. The first group of methods includes the Euler type II. These models are recommended for modeling sewage systems in Germany [7], [8], as well as in Poland [3], [16], [17], in the presumption that Polish climatic conditions are similar to the German ones. The shapes of the Euler type II (in a dimensional system), were not, however, subjected to appropriate verification in Polish climatic conditions, which will be done in this paper.

Standard hyetographs based on historical rainfall records are created by statistical analysis of data on selected precipitation phenomena [12], [13]. They are usually presented in the form of a cumulative hyetograph dimensionless mass curves. The oldest is the method 
proposed by Huff [18] in 1967, who proposed the division of precipitation events into 4 groups, called quartiles determining in which part of the rainfall duration its maximum intensity occurred. On this basis, he created the so-called quartile charts illustrating changes in precipitation over time. Huff curves are therefore a probabilistic representation of the ratio of cumulative precipitation amounts to the corresponding cumulative duration, in the form of the so-called probability isopleths. Huff curves have found widespread use for analyzing rainfall variability, including by Pani and Haragan [19], Bonta and Rao [20], Terranova and Iaquinta [21] or Pan et al. [22]. Bonta [23] has further refined Huff's methodology.

Analysis of precipitation time variability for the purposes of creating reliable reference hyetographs is of many researchers' interest. In the current studies, precipitation data were divided into groups according to their duration (a genetic type of precipitation). Often, for each group $(t)$, separate reference hyetographs were created. However, there is a lack of studies that would take into account the frequency with the exceedance $(C)$ of given precipitation occurrence, which is necessary for application for modeling the reliability of sewage systems operation. At the same time, parameters of hyetograph describing unevenness in time are not specified, which should be taken into account when comparing their shapes.

\section{MEthod of ANALYSIS}

In the time-spatial structure of precipitation occurring in Poland three genetic types of precipitation are distinguished: convective - with duration up to approx. 2 hours, frontal with a duration usually between 2 and 12 hours and low-pressure - usually over 12 hours. In adaptation to genetic types of precipitation, unevenness in time $t$ parameters $h$ and $i$ can be compared in individual groups of their durations, i.e. $t \in[10 ; 120] \mathrm{min}, t \in(120 ; 720] \mathrm{min}$, and $t>720 \mathrm{~min}$, including occurrence frequency: $C \in\{1,2,5,10\}$ years which are accepted for dimensioning or modeling of the sewage system according to PN-EN 752:2017 [5] and DWA-A118:2006 [7].

Precipitation hyetographs can be characterized in terms of unevenness in time by two geometric indicators:

- location of the interval $\Delta t$ with the cut off $\left(t_{\text {peak }}\right)$ peak of maximum precipitation $h_{\max }(\Delta t)$,

- location of the interval $\Delta t$ with the cut off $\left(t_{c g}\right)$ the center of gravity of the hyetograph $P_{c} / 2$,

for a variable (dimensionless systems) or constant (dimensional systems) step discretization time $\Delta t$, defined as:

$$
\begin{gathered}
r=\frac{t_{\text {peak }}\left(h_{\max }(\Delta t)\right)}{T} \\
r_{c g}=\frac{t_{c g}\left(P_{c} / 2\right)}{T}
\end{gathered}
$$

where: $r$ - peak position ratio for the maximum interval precipitation height $\left(h_{\text {max }}(\Delta t)\right),-; t_{\text {peak }}\left(h_{\max }(\Delta t)\right)$ - peak time of peak interval precipitation, min; $T$ - total duration of rainfall, min; $r_{c g}$ - hyetograph center of the gravity position indicator, $-; t_{c g}\left(P_{c} / 2\right)$ - time of the center of gravity of the hyetograph (for $P_{c} / 2$ ), $\min ; P_{c}-$ cumulative (total) rainfall amount (in time $T), \mathrm{mm}$.

For the needs of mass hyetographs created at work - in dimensionless systems, a fixed number of 10 intervals was assumed $\Delta t$ that allows to position the peak/peaks $(r)$ of the maximum interval height (intensity) of precipitation, with an accuracy of $0.1 T$. This forces the use of different, discretely set values of time intervals: $\Delta t \in\{1.0 \mathrm{~min}$ (for $T=10 \mathrm{~min}$ ); $1.5 \mathrm{~min}(T=15 \mathrm{~min}) ; 2.0 \mathrm{~min}(T=20 \mathrm{~min}) ; \ldots ; 5.0 \mathrm{~min}(T=$ $50 \mathrm{~min}) ; \ldots ; 144 \mathrm{~min}(T=1440 \mathrm{~min}) ; \ldots ; 432 \mathrm{~min}(T=4320$ $\min )\}$. For the purposes of creating hyetographs of precipitation in the dimensional systems, a constant value of the time interval will be used: $\Delta t=5.0 \mathrm{~min}$, which determines their variable number.

Three mass indicators were defined for the analysis of mass distribution on hyetographs:

$m_{1}-$ as the cumulative ratio of precipitation height (mass) for the time from $t=0$ to $t=t_{\text {peak }}$ (before the cut off peak of maximum rainfall $\left.h_{\max }(\Delta t)\right)$, to the cumulative amount of precipitation for the time from $t=t_{\text {peak }}$ to $t=T$ (after peak):

$$
m_{1}=\frac{\sum_{0}^{t_{\text {peak }}} h_{i}}{\sum_{t_{\text {peak }}}^{T} h_{i}}
$$

$m_{2}-$ as the ratio of the maximum interval height (mass) of precipitation to the total height:

$$
m_{2}=\frac{h_{\mathrm{max}}(\Delta t)}{P_{c}(T)}
$$

$m_{3}-$ as the ratio of the accumulated height (mass) of precipitation for the time from $t=0$ to $t=0,33 T$, to the total height:

$$
m_{3}=\frac{\sum_{0}^{0.33 T} h_{i}}{P_{c}(T)}
$$

where: $h_{i}$ - instantaneous height of rainfall (for $\Delta t=1 \mathrm{~min}$ ), $\mathrm{mm} ; h_{\max }(\Delta t)-$ maximum interval $(\Delta t)$ precipitation height, $\mathrm{mm} ; P_{c}(T)$ - total rainfall height (in time $T$ ), $\mathrm{mm} ; 0,33 T$ - first $1 / 3$ part of the total rainfall duration $(T)$, min.

To describe unevenness during intensity $(i)$ an indicator was defined as the ratio of the maximum interval value to the average value - from the entire duration of the precipitation $(T)$, i.e. respectively:

$$
n_{i}=\frac{i_{\max }(\Delta t)}{i_{m}(T)}
$$

where: $i_{\max }(\Delta t)-$ maximum interval $(\Delta t)$ rainfall intensity, $\mathrm{mm} / \mathrm{min} ; i_{m}(T)$ - mean rainfall intensity (over time $T$ ), $\mathrm{mm} / \mathrm{min}$.

The indicators: $r, r_{s c}, m_{1}, m_{2}$ are dedicated to the similarity analysis of real shapes of hyetographs in dimensionless 
systems - variable value of $\Delta t=0.1 T$. The other 2 indicators: $m_{3}$ and $n_{i}$ are dedicated to comparative analyzes of hyetographs' shapes in dimensional systems - fixed value $\Delta t$ $=5 \mathrm{~min}$.

\section{Study AREA AND DATA USED}

The research material is historical records of precipitation data from the measuring station of the Institute of Meteorology and Water Management - National Research Institute (IMGW-PIB) in Wroclaw and local precipitation monitoring networks of The Municipal Water and Sewage Company (MPWiK) in Wroclaw. Monitoring stations are located at an altitude of approx. $120 \mathrm{~m}$ above sea level. Maximal daily precipitation sum is $74.4 \mathrm{~mm}$.

Available data strings from precipitation registration at the IMGW-PIB station in Wroclaw include the periods: 1960-2008 - registration on paper strips, and 2005-2018 electronic registration with a time step of 1 minute. The MPWiK precipitation measurement network in Wroclaw has been operating since 2012. It currently consists of 11 weight rain gauges (TRwS 203 and TRwS 200 types). The available precipitation recording series range from approx. 1 to 7 years.

To assign the frequency of precipitation occurrence: $C \in$ $\{1,2,5,10\}$ years, a model of maximum rainfall for Wroclaw was developed (1968-2017), in the form:

$$
h(t, C)=5,276 C^{0.313} t^{0.281-0.00175 C}
$$

for the range: $t \in[10 ; 1440] \mathrm{min}$ and $C \in[1 ; 50]$ years necessary to determine the threshold values for precipitation $h(t, C)$ in terms of $t \in[10 ; 1440] \mathrm{min}$ and $C \in[1 ; 10]$ years. On this basis, for the statistical analysis of rainfall, precipitation of exceedance frequencies $C(t) \geq 1$ year were selected, obtaining the population of 126 precipitations, which were grouped by duration into 3 groups (and 7 subgroups). Then, due to the occurrence frequency, precipitation were classified into 4 classes of exceedance frequency. The amount of precipitation in individual groups of both classifications is summarized in Table I.

\section{RESUlTS AND DisCUSSION}

Cluster analysis using the Ward method was used to extract homogeneous - similar subsets of the objects of the studied population. This method belongs to hierarchical methods. The measure of similarity is the function of the bond distance of object pairs. Euclidean distance is most commonly used. Fig. 1 represents the dendrogram being the result of grouping the analyzed shapes of 126 precipitation from measuring stations in Wroclaw. The analysis of the chart made it possible to determine the cut-off distance of approx. 3 , which leads to the division of precipitation into 4 clusters, with clearly different courses of intensity changes over time.

TABLE I: NUMBER OF PRECIPITATION IN SEPARATE TIME GROUPS AND EXCEEDANCE CLASSES

\begin{tabular}{|c|c|c|c|c|c|}
\hline \multicolumn{3}{|c|}{ Classification } & \multicolumn{3}{|c|}{ Number of rainfall (percent) } \\
\hline Duration & $t \leq 120 \mathrm{~min}$ & $\leq 60 \mathrm{~min}$ & $60(47 \%)$ & 75 & 126 \\
\hline
\end{tabular}

\begin{tabular}{|c|c|c|c|c|c|}
\hline & & $(60 ; 120] \mathrm{min}$ & $15(12 \%)$ & $(59 \%)$ & $(100 \%)$ \\
\hline & $\begin{array}{c}t \in(120 ; 720] \\
\min \end{array}$ & $\begin{array}{l}(120 ; 180] \mathrm{min} \\
(180 ; 360] \mathrm{min} \\
(360 ; 720] \mathrm{min}\end{array}$ & $\begin{array}{c}9(7 \%) \\
3(2 \%) \\
14(11 \%)\end{array}$ & $\begin{array}{c}26 \\
(21 \%)\end{array}$ & \\
\hline & $t>720 \mathrm{~min}$ & $\begin{array}{c}(720 ; 1440] \mathrm{min} \\
>1440 \mathrm{~min}\end{array}$ & $\begin{array}{l}13(10 \%) \\
12(10 \%)\end{array}$ & $\begin{array}{c}25 \\
(20 \%)\end{array}$ & \\
\hline \multirow{4}{*}{$\begin{array}{l}\text { Frequency } \\
\text { of } \\
\text { occurrence }\end{array}$} & \multicolumn{2}{|c|}{$C \in[1 ; 2)$ years } & \multicolumn{2}{|c|}{$56(45 \%)$} & \\
\hline & \multicolumn{2}{|c|}{$C \in[2 ; 5)$ years } & \multicolumn{2}{|c|}{$37(29 \%)$} & 126 \\
\hline & \multicolumn{2}{|c|}{$C \in[5 ; 10)$ years } & \multicolumn{2}{|c|}{$18(14 \%)$} & $(100 \%)$ \\
\hline & \multicolumn{2}{|c|}{$C \geq 10$ years } & \multicolumn{2}{|c|}{$15(12 \%)$} & \\
\hline
\end{tabular}

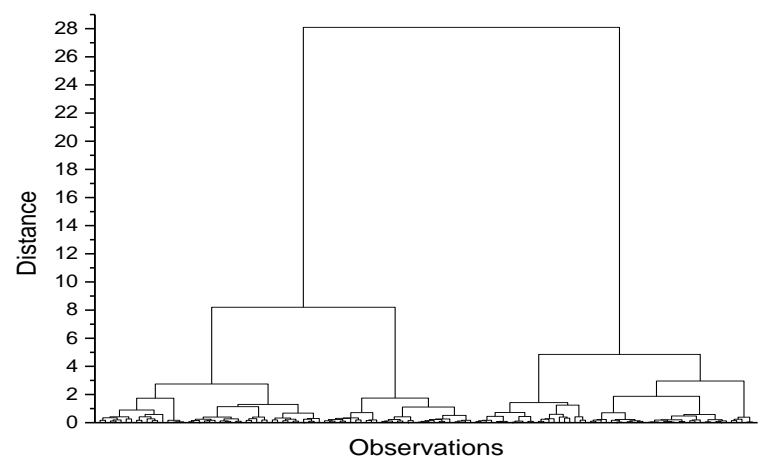

Fig. 1. Dendrogram of 126 precipitation grouping using the ward method.

The most numerous cluster no. 1 covers $34 \%$ of the analyzed precipitation phenomena. Precipitation belonging to this cluster is characterized by maximum height increases occurring in the middle of their duration. Cluster No. 4 (25\% of observations) is the second largest, in which the highest amount increases occur $1 / 3$ of the duration. Cluster no. 2 has a similar size $(23 \%)$. Cluster no. 3 covers only $18 \%$ of precipitation.

The results of agglomeration of 126 precipitation using the Ward method showed the existence of 4 clusters with similar courses of sum curves within the distinguished groups. This allows using another method of precipitation grouping the method of $k$-means. This method belongs to non-hierarchical methods. It consists of dividing the population into a number of clusters predicted in advance. For grouping precipitation using the method $k$-means number of clusters was assumed as $k=4$. Fig. 2 shows the rainfall sum curves in 4 clusters with the median curves plotted on the graphs. As a result of grouping of precipitation by this method, more expressive clusters were obtained compared to the results of the grouping by the Ward method - the bundles of most precipitation sum curves are located closer to the respective medians.

In the case of precipitation grouping by the $k$-means method, the most numerous cluster is cluster no. 2 covering 37 precipitation (30\% of the analyzed population). Cluster no. 3 covering 35 precipitations ( $28 \%$ of the population) is the second largest. Precipitation belonging to cluster no. 1 , in the number 17 ( $21 \%$ of the population), has peaks of intensity increase shifted to the second half of the duration. Precipitation belonging to cluster no. 4, with the smallest number of 27 ( $21 \%$ of the population), has peaks of intensity increase located in the first $1 / 5$ of the duration (Fig. 2). Clusters no. 3 and 4 are characterized by the largest increases in relative, interval height in $1 / 3$ of the duration of precipitation, which makes them similar to the Euler rainfall model. Method of $k$-means, therefore, gives qualitatively better results of rainfall grouping compared to the Ward 
method.
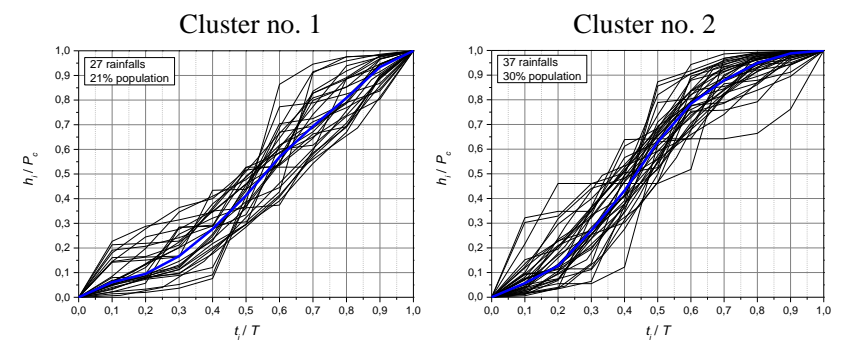

Cluster no. 3
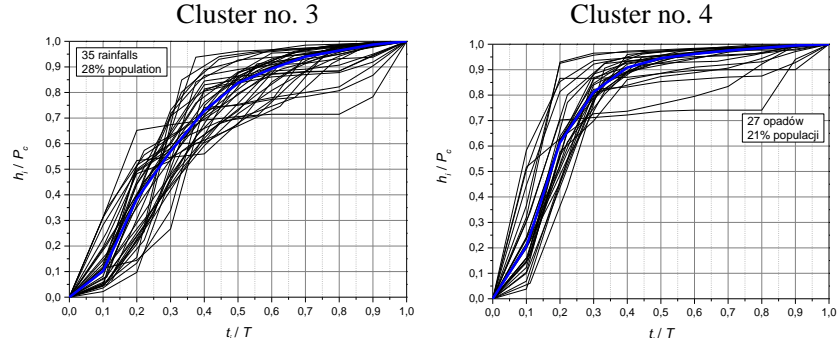

Fig. 2. Dimensionless rainfall mass curves with median for 4 clusters separated by the $k$-means method.

The results of precipitation grouping by means of cluster analysis by the method of $k$-means allowed for initial verification of relative position $(r)$ peaks of the largest, interval height (intensity) of precipitation. Namely, it was shown (Fig. 2) that almost half of the analyzed precipitation (49\% of the population) has a peak of cumulative height located at $1 / 3$ of the initial duration during in which time over $2 / 3$ of the height (mass) is deposited of total precipitation. Therefore, the features of mass distribution on dimensionless hyetographs belonging to the clusters no. 3 and 4 are similar to the Euler type II standard. These clusters include the majority -48 (out of 75) convective precipitations (C) and 3 frontal precipitations $(\mathrm{F})$ - from the border between $\mathrm{C}$ and $\mathrm{F}$, i.e. $T \leq 180 \mathrm{~min}$, more precisely $T<150 \mathrm{~min}$. These precipitations will therefore be subjected to a detailed quantitative analysis of the similarity of the histogram shapes to the Euler II pattern.

Fig. 3 presents graphs of the sum curves of 51 of the analyzed precipitation together with the calculated median curve, which shows that in $1 / 3$ of their initial duration, the rainfall mass reaches approx. $75 \%$.

For selected 51 precipitations, the calculated values of dimensionless indicators are within: $r \in[0.05 ; 0.44] ; r_{c g} \in$ $[0.09 ; 0.36] ; m_{1} \in[0.16 ; 2.56] ; m_{2} \in[0.17 ; 0.61] ; m_{3} \in[0.48$; $0.97] ; n_{i} \in[1.59 ; 6.19]$.

It can be seen that both the peak location indicator $r$ and the center of gravity indicator $r_{c g}$, do not exceed 0.44 , so they slightly exceed 0.33 , characteristic of the Euler model. Indicator value $m_{1}$ means that the mass of precipitation before the peak to the mass after the peak has a maximum ratio of $2.56: 1$. The ratio of the maximum interval precipitation to the total height does not exceed the value $m_{2}=0.61$, which means it can be up to 6.1 times the average $\left(h_{i} / P_{c}=0.1\right)$. The indicator values of particular interest are $m_{3}$ - the ratio of accumulated precipitation mass for $1 / 3$ of the initial time to the total mass. Namely, the indicator values $m_{3}$ change in the range of 0.48 to even 0.97 . Similarly, the indicator values are characteristic $n_{i}-$ as the ratio of the maximum interval intensities to the average values over the entire period of precipitation: from $n_{i}=1.59$ - low rainfall (maximum range values are approx. 1.5 times larger than the average), up to even $n_{i}=6.19-$ high rainfall unevenness (maximum range values are over six times higher than the average). A dimensionless hyetograph was prepared for the selected 51 precipitations, shown in Fig. 4.

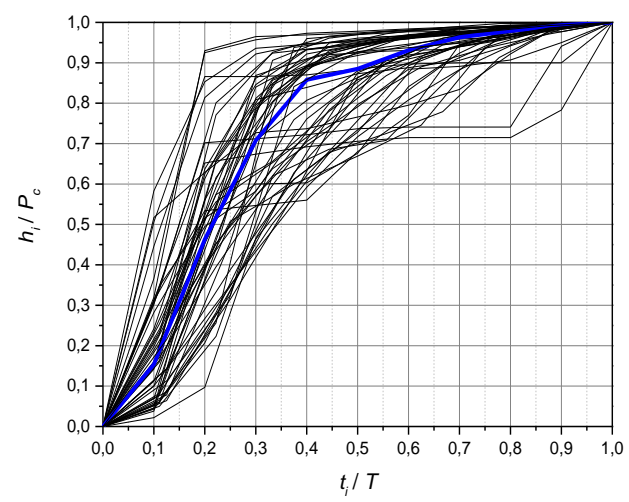

Fig. 3. Dimensionless mass curves with a median for 15 convective $(C)$ and 10 frontal (F with $T \leq 180 \mathrm{~min}$ ) rainfall from clusters no. 3 and 4 (for $k=4$ ).

In Fig. 4, the ranges of changes in measured relative interval values $(\Delta t=0.1 T)$ precipitation amount $\left(h_{i} / P_{c}\right)$, depicted using so-called box charts that allow to include on the pictogram information on the location, dispersion, and shape of the empirical distribution of the studied size. The whiskers were limited to $10 \%$ and $90 \%$ of the data set percentile (which are identified in the literature by Huff [18] and Bonta [23], with confidence intervals at $10 \%$ and $90 \%$ respectively). It should be noted that discrete median values in Fig. 4 were determined for interval increments of precipitation, in contrast to the median illustrated in Fig. 3, where these values were determined on the basis of total mass curves. There are no differences in the peak location itself: $r$ $=0.2 t_{i} / T$, i.e. in $1 / 5$ of the duration of precipitation. However, it should be remembered that the Euler type II model is a dimensional hyetograph based on IDF/DDF curves, so its dimensionless forms (according to Fig. 3 and 4) can only be used to determine the location of the peak maximum height precipitation intensity, or more precisely the range containing the peak - with an accuracy of 1/10 T.

The features of mass distribution on dimensionless hyetographs of 51 tested precipitations from Wroclaw are similar to the Euler type II standard. This observation, however, requires confirmation in a detailed quantitative assessment - in the dimensional system. For comparative analyses of the shapes of 51 real (dimensional) precipitation hyetographs, it was necessary to develop standard Euler type II precipitation - from DDF/IDF curves for this station. The model of maximum precipitation heights (according to formula 7) was used to create DDF curves, from which rainfall heights were calculated for $t \in[5 ; 180] \mathrm{min}$ and $C \in$ [1; 10] years, necessary for the construction of 28 Euler models - for 7 duration times: $T=30,45,60,75,90,120$ and $180 \mathrm{~min}$ (assumed values $T$, in terms of duration of real precipitation, they meet the criterion of division into 3 equal parts) and in 4 frequency classes: $C=1,2,5$ and 10 years.

For the developed Euler type II rainfall, reference mass distributions were examined by indicator $m_{3}-$ as the ratio of accumulated precipitation for the time from $t=0$ to $t=0,33 T$ 
to the total height over time $t=T$ (according to formula 5). Mass distributions by indicator $m_{3}$ proved to be almost identical, independent of $T$ and $C$. The average value of the indicator was $m_{3}=0.741$. The model differentiation of intensity unevenness in time of Euler's model rainfall was also analyzed by indicator $n_{i}-$ as the ratio of the maximum interval intensity of precipitation $(\Delta t=5 \mathrm{~min})$ to average intensity over time $T$ (according to formula 6). The calculation results are presented in Table II.

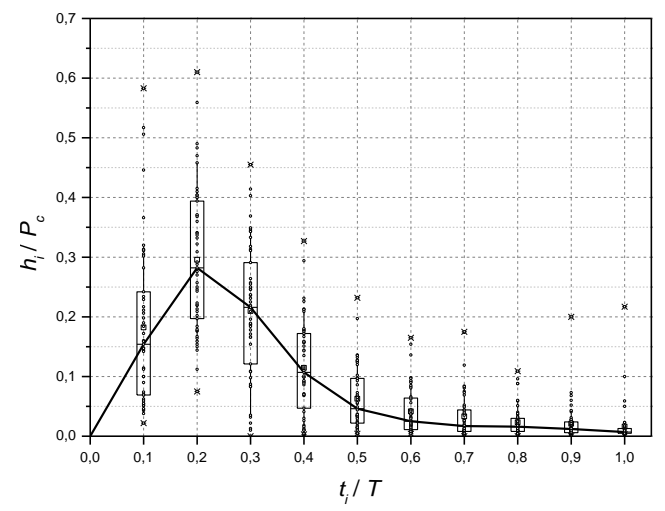

Fig. 4. Dimensionless hyetograph for 51 precipitation with box charts with measurement results.

In the developed Euler type II reference rainfall for Wroclaw, the unevenness according to the indicator $n_{i}$ is different - from 3,64 to 13,99 in individual durations $T \in[30$; 180] min, but independent of occurrence frequency $(C)$ of precipitation. Average indicator value $n_{i}=7.71$. The value of the peak location indicator in Euler type II models is on average $r=0.285$ - change in the scope of 0.25 for $T=30$ min to 0.32 for $T=180 \mathrm{~min}$, independently from $C$.

To assess mass distribution and unevenness in intensity of (i) real 51 precipitations, the following indicators were used: $r, m_{3}, n_{i}$-dedicated to quantitative similarities to the Euler type II standard. For the 51 analyzed precipitation values of the indicators - in relation to the actual duration of precipitation $T: r \in[0.02 ; 0.39]$, mean value: $0.17 ; m_{3} \in[0.43$; $0.97]$, mean value: $0.72 ; n_{i} \in[1.36 ; 9.51]$, mean value: 3.70 .

For comparative purposes, of real precipitation hyetographs with Euler type II model hyetographs, it was necessary to use a different methodology for interpreting the duration parameter $(T)$ of actual precipitation. Namely, to maintain the principle of creating Euler model precipitation, i.e. meeting the divisibility of the duration of precipitation into 3 equal parts, and at the same time its divisibility into intervals (with a time step) $\Delta t=5 \mathrm{~min}$, the actual precipitation duration $(T)$ had to be corrected up to their model duration $\left(T^{\prime}\right)$. At stake here is only its correction upwards - elongation of time so as not to lose the weight (height) of actual precipitation. On this basis, it was made re-analysis of real precipitation of hyetographs with Euler model hyetographs for model time $T^{\prime}$. The following indicators were used again for quantitative assessments: $r, m_{3}$ and $n_{i}$-in relation to time $T^{\prime}: r^{\prime} \in[0.02 ; 0.29]$, mean value: $0.15 ; m_{3}{ }^{\prime} \in[0.53 ; 0.96]$, mean value: $0.80 ; n_{i}^{\prime} \in[1.59 ; 10.26]$, mean value: 4.09 .

The above values of indicators for model time $T^{\prime}$ allow to draw methodically correct conclusions regarding the comparison of 51 dimensional hyetographs of real precipitation from Wroclaw with 28 Euler type II standards:

- Index values $r$ peak height location $h_{\max }(\Delta t)$ relative to time $T^{\prime}$ on 51 hyetographs of actual precipitation include: $r^{\prime} \in[0.02 ; 0.29]$, with a mean value $r^{\prime}=0.15$; The value of this indicator in Euler type II standards change in the range of: $r \in[0.25 ; 0.32]$, on average $r=0.285$ - for the range $T=T^{\prime} \in[30 ; 180] \mathrm{min}$; Both peaks occur in the first $1 / 3$ of precipitation duration $T=T^{\prime}$.

- Mass distribution on 51 dimensional hyetographs are variable in the range: $m_{3}{ }^{\prime} \in[0.53 ; 0.96]$, however, the mean value: $m_{3}{ }^{\prime}=0.80$ is close to constant value $m_{3}{ }^{\prime}=$ 0.741 - for 28 Euler type II models; In both cases, the main precipitation mass is located in the first $1 / 3$ of the duration $T=T^{\prime}$.

- The unevenness precipitation over 51 hyetographs was significant: $n_{i}^{\prime} \in[1.59 ; 10.26]$, average $n_{i}^{\prime}=4.09$; In Euler type II standard precipitation, the unevenness was similar - in the range $n_{i} \in[3.64 ; 13.99]$, average $n_{i}=7.71$. These values should be considered similar - within the accuracy class of hydrological calculations (random phenomena).

TABLE II: THE MAXIMUM INTERVAL RATIOS ( $\Delta T=5$ MIN) PRECIPITATION INTENSITY (IN MM/MIN) TO THEIR AVERAGE VALUES OVER TIME $T$ FOR EULER TYPE II MODELS

\begin{tabular}{ccccccccc}
\hline \hline $\begin{array}{c}\text { Frequency } \\
\text { of rainfall } \\
\text { occurrence }\end{array}$ & 30 & 45 & 60 & 75 & 90 & 120 & 180 & Mean \\
\cline { 2 - 8 }$C=1$ year & 3.64 & 4.88 & 5.99 & 7.04 & 8.03 & 9.90 & 13.23 & 7.53 \\
$C=2$ years & 3.65 & 4.89 & 6.02 & 7.06 & 8.06 & 9.94 & 13.30 & 7.56 \\
$C=5$ years & 3.74 & 5.05 & 6.23 & 7.35 & 8.42 & 10.39 & 13.99 & 7.88 \\
$C=10$ years & 3.74 & 5.05 & 6.23 & 7.35 & 8.42 & 10.39 & 13.99 & 7.88 \\
Mean & 3.69 & 4.97 & 6.12 & 7.20 & 8.23 & 10.16 & 13.63 & 7.71 \\
\hline \hline
\end{tabular}

\section{Summary AND FinAl CONCLUSIONS}

For IMGW-PIB and MPWiK S.A. stations in Wroclaw, based on the maximum precipitation model, time series of maximum rainfall occurrences were determined - for the assumed times and frequency of exceedance $(C \geq 1$ year, $C \geq$ 2 years $C \geq 5$ years and $C \geq 10$ years). To examine the shapes of local hyetographs, precipitation with exceedance frequencies of $C(T) \geq 1$ year were selected for statistical analysis, which was then genetically grouped - by duration, on precipitation: convective (with $T \leq 120 \mathrm{~min}$ ), frontal ( $T \in$ $(120 ; 720] \mathrm{min})$ and low-pressure $(T>720 \mathrm{~min})$.

To group precipitation due to the similarity of genetic features, 2 research methodologies were used: cluster analysis using the Ward and $k$-means methods. These methods, and especially the $k$-means method, proved to be useful for selecting precipitation in terms of dimensionless hyetographs shapes. Grouping of precipitation using the $k$-means method has allowed the attribution of 126 precipitation (with $C(T) \geq 1$ year) up to 4 characteristic clusters, of which clusters no. 3 and 4 showed features similar to the Euler type II standard. Statistical analysis of the similarity of shapes of hyetographs was performed within the separated genetic clusters, with the determination of mass distribution parameters and unevenness in time, by 6 indicators defined in the paper.

51 precipitations were selected to verify the Euler type II 
pattern. As a result of the comparisons, it was shown that the mass distributions on 51 dimensional hyetographs are similar to the Euler type II standard. However, the peak height indicator value of the maximum height $h_{\max }(\Delta t)$ differs: $r \approx$ 0.2 for the tested precipitation, relative to $r \approx 0.3$ - on Euler type II standard. Generally, it should be stated that the Euler type II standard is suitable for the description of precipitation in Wroclaw. The tested discrepancies fall within the accuracy class of hydrological measurements and calculations related to random phenomena.

\section{CONFLICT OF INTEREST}

The authors declare no conflict of interest.

\section{AUTHOR CONTRIBUTIONS}

$\mathrm{KW}, \mathrm{BK}, \mathrm{MN}$ and $\mathrm{AK}$ - conceptualization and methodology; BK - resources; KW - investigation; AK formal analysis; $\mathrm{KW}, \mathrm{BK}, \mathrm{MN}$, and $\mathrm{AK}$ - writing (original draft preparation); KW and $\mathrm{BK}$ - writing (review, editing and visualization); AK - supervision. All authors had approved the final version.

\section{REFERENCES}

[1] IPCC, Climate Change. Impacts, Adaptation, and Vulnerability (Part A: Global and Sectoral Aspects), Contribution of Working Group II to the Fifth Assessment Report of the Intergovernmental Panel on Climate Change, Cambridge University Press, 2014.

[2] B. Kaźmierczak and A. Kotowski, "The influence of precipitation intensity growth on the urban drainage systems designing," Theor. Appl. Climatol., vol. 118, no. (1-2), pp. 285-296, Oct. 2014.

[3] A. Kotowski, Podstawy bezpiecznego wymiarowania odwodnień terenów, Warsaw: Wyd. Seidel-Przywecki, 2015.

[4] A. Kotowski and M. Nowakowska, "Standards for the dimensioning and assessment of reliable operations of area drainage systems under conditions of climate change," Technical Transactions / Environmental Engineering, no. 1, pp. 125-139, 2018.

[5] Drain and Sewer Systems Outside Buildings - Sewer System Management, PN-EN 752, 2017.

[6] K. Wartalska, M. W. Nowakowska, and B. Kaźmierczak, "Verification of storm water reservoirs operation in hydrodynamic modeling," in Proc. 9th IWA Eastern European Young Water Professionals Conference, 2017.

[7] Hydraulische Bemessung und Nachweis von Entwässerungssystemen, DWA-A118, 2006.

[8] DVWK, "Arbeitsanleitung zur Anwendung Niederschlag-Abflub-Modellen in kleinen Einzugsgebieten," Hamburg, 1984.

[9] T. G. Schmitt et al., "Hydraulische Bemessung und Nachweis von Entwässerungssystemen," Hennef: DWA, 2000.

[10] SCS, "Urban hydrology for small watersheds," Washington: Engineering Division, Soil Conservation Service, US Department of Agriculture, 1986.

[11] V. T. Chow, D. R. Maidment, and L. W. Mays, Applied Hydrology, New York: McGraw-Hill, 1988.

[12] D. Veneziano and P. Villani, "Best linear unbiased design hyetograph," Water Resour. Res., vol. 35, no. 9, pp. 2725-2738, Sep. 1999.

[13] G. F. Lin, L. H. Chen, and S. C. Kao, "Development of regional design hyetographs," Hydrol. Process., vol. 19, no. 4, pp. 937-946, March 2005.

[14] S. Cazanescu and. R. A. Cazanescu, "New hydrological approach for environmental protection and floods management," Bulletin UASVM Agriculture, vol. 66, no. 2, pp. 63-70, Jan. 2009.

[15] C. J. Keifer and H. H. Chu, "Synthetic storm pattern for drainage design," J. Hydr. Eng. Div., vol. 83, no. 4, pp. 1-25, 1957.

[16] B. Kaźmierczak and A. Kotowski, "Weryfikacja przepustowości kanalizacji deszczowej w modelowaniu hydrodynamicznym," Wroclaw: Oficyna Wyd. Politechniki Wroclawskiej, 2012.

[17] A. Kotowski, B. Kaźmierczak, and M. Nowakowska, "Analysis of the drainage system load in case of the predicted increase in frequency and intensity of rain due to climate change," Ochr. Sr., vol. 35, no. 1, pp. 25-32, Jan. 2013.

[18] F.A. Huff, "Time distribution of rainfall in heavy storms," Water Resour. Res., vol. 3, no. 4, pp. 1007-1019, Dec. 1967.

[19] E. A. Pani and D. R. Haragan, "A comparison of Texas and Illinois temporal rainfall distributions," in Proc. Fourth Conference on Hydrometeorology, Boston: American Meteorological Society, 1981.

[20] J. V. Bonta and A. R. Rao, "Factors affecting development of Huff curves," T. ASAE, vol. 30, no. 6, pp. 1689-1693, 1987.

[21] O. G. Terranova and P. Iaquinta, "Temporal properties of rainfall events in Calabria (southern Italy)," Nat. Hazard. Earth Sys., vol. 11, no. 3, pp. 751-757, March 2011.

[22] C. Pan, X. Wang, L. Liu, H. Huang, and D. Wang, "Improvement to the huff curve for design storms and urban flooding simulations in Guangzhou, China," Water, vol. 9, no. 6, pp. 411, June 2017.

[23] J. V. Bonta, "Development and utility of Huff curves for disaggregating precipitation amounts," Appl. Eng. Agric., vol. 20, no. 5, pp. 641-652, Sep. 2004.

Copyright $\odot 2020$ by the authors. This is an open access article distributed under the Creative Commons Attribution License which permits unrestricted use, distribution, and reproduction in any medium, provided the original work is properly cited (CC BY 4.0).

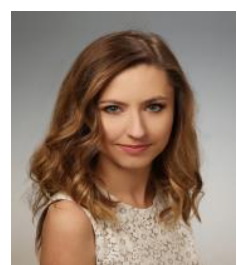

K. Wartalska was born in Oława, Poland, in 1990 She obtained her master's degree in environmental engineering from the Wrocław University of Science and Technology, Wrocław, Poland, in 2014. Since 2014, she started Ph.D. studies at the Faculty of Environmental Engineering, at the Wrockaw University of Science and Technology, Poland, with the thesis entitled, "analysis of the rainfal hyetographs for the modeling of the drainage systems operation" defented with honors in 2019.

In 2018, she started her professional career as an assistant at the faculty of Environmental Engineering at the Wrocław University of Science and Technology, which is constantly the basic place of her employment to this day.

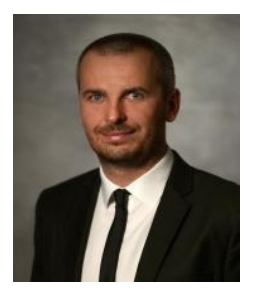

B. Kaźmierczak was born in Jelenia Góra, Poland, in 1982. He obtained his master's degree in environmental engineering from the Wrocław University of Science and Technology, Wrocław, Poland, in 2007. In 2007, he started PhD studies at the Faculty of Environmental Engineering, at the Wrocław University of Science and Technology, Poland, with the thesis entitled "simulation studies of stormwater overflows and stormwater separators operation in the unsteady motion conditions to support the design of the drainage systems" defended with honors in 2011 .

In 2011, he started work as an assistant at the Faculty of Environmental Engineering at the Wroclaw University of Science and Technology, which is continuously the basic place of his employment until today. In 2012, he was promoted to the position of the scientific and teaching adjunct and simultaneously, he took the position of the deputy director for scientific Research and cooperation with the industry in the Institute of Environmental Protection Engineering at the Wroclaw University of Science and Technology, which he held until 2014. In 2016, he took the function of the vice-dean for student and organizational cases, which he have held to this day.

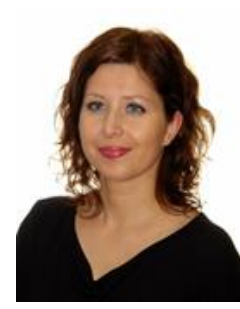

M. Nowakowska was born in Oława, Poland, in 1981. She obtained her master's degree in environmental engineering from the Wrocław University of Environmental and Life Science, Poland in 2008. Since 2011, she started Ph.D. studies at the Faculty of Environmental Engineering, at the Wrocław University of Science and Technology, Poland. In 2016, she completed her $\mathrm{PhD}$ thesis 'Identification of hydrological and hydraulic parameters of urban catchment area in hydrodynamic modelling of the SWMM'.

Since 2016, she started her career as an assistant and now as an adjunct at the Department of Water Supply and Sewerage Systems at the Wrocław University of Science and Technology. 


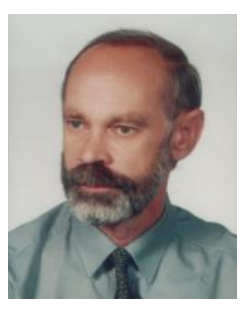

A. Kotowski was born in Leśna, Poland, in 1951. He obtained his master's degree in sanitary engineering from the Wrocław University of Science and Technology, Wrocław, Poland, in 1974. In the same year, he started work as an assistant at the Institute of Environmental Protection Engineering at the Wroclaw University of Science and Technology. In 1980, he defended $\mathrm{PhD}$ degree with honors at the Faculty of Sanitary Engineering, at the Wrocław University of Science and Technology, Poland, with the thesis entitled "Model studies of the impact of selected design parameters of infiltration water radial intakes on their performance".
In 1980, he was promoted to the position of the scientific and teaching adjunct. His habilitation thesis entitled "Basics of dimensioning side storm overflows with a throttle pipe" lead to the award of the title of Doctor of Science in the discipline of environmental engineering. In the years 1999-2005, he held the position of the vice-dean for didactic cases at the Faculty of Environmental Engineering. Since 2001, he works as an associate professor. In 2012, he obtained the title of professor of technical sciences. In the years 2004-2014 he was the head of Scientific Department of Sewage Removal in the Institute of Environmental Protection Engineering of Wroclaw University of Science and Technology, and since 2014, he is heading the Department of Water Supply and Sewerage Systems. 